\title{
Epithelial-myoepithelial carcinoma of the parotid gland, unusual malignancy radiologically simulating a benign lesion: case report
} Irene Piscioli ${ }^{1}$, Luca Morelli2 ${ }^{2}$, Andrea Falzone ${ }^{3}$, Franca Del Nonno ${ }^{4}$, Marinella Neri ${ }^{3}$, Zorika Christiana Di Rocco ${ }^{5}$, Alessia Catalucci ${ }^{6}$, Salvatore Donato ${ }^{7}$ and Stefano Licci*4

Address: ${ }^{1}$ Department of Radiology, Civil Hospital of Budrio, Italy, ${ }^{2}$ Department of Pathology, "S. Maria del Carmine" Hospital, Rovereto, Italy, ${ }^{3}$ Department of Radiology, "S. Maria del Carmine" Hospital, Rovereto, Italy, ${ }^{4}$ Department of Pathology, National Institute for Infectious Diseases "L. Spallanzani" IRCCS, Rome, Italy, ${ }^{5}$ Department of Oncology, "Istituto Dermopatico dell'Immacolata", Rome, Italy, ${ }^{6}$ Department of Radiology,

"S. Salvatore" Hospital, L'aquila, Italy and ${ }^{7}$ Department of Radiology, Civil Hospital of Bentivoglio, Italy

Email: Irene Piscioli - irenedelirium@libero.it; Luca Morelli - Luca.Morelli@apss.tn.it; Andrea Falzone - Andrea.Falzone@apss.tn.it; Franca Del Nonno - delnonno@inmi.it; Marinella Neri - marinellan@hotmail.com; Zorika Christiana Di Rocco - zcdirocco@yahoo.com; Alessia Catalucci - alessiacat@tiscali.it; Salvatore Donato - salvatore.donato@ausl.bo.it; Stefano Licci* - licci@inmi.it

* Corresponding author

Published: 16 October 2007

International Seminars in Surgical Oncology 2007, 4:25 doi:10.1 186/1477-7800-4-25

This article is available from: http://www.issoonline.com/content/4///25

(C) 2007 Piscioli et al; licensee BioMed Central Ltd.

This is an Open Access article distributed under the terms of the Creative Commons Attribution License (http://creativecommons.org/licenses/by/2.0), which permits unrestricted use, distribution, and reproduction in any medium, provided the original work is properly cited.
Received: 4 July 2007

Accepted: 16 October 2007

\begin{abstract}
Background: Ultrasound (US), Computed Tomography (CT) and Magnetic Resonance Imaging (MRI) are widely used in the clinical diagnosis of parotid gland tumors and their efficacy in identifying benign lesions is well documented. However, problems arise when facing some malignant lesions. Only few cases of salivary gland low grade malignant tumors have been previously reported in the literature complete with the radiological features.
\end{abstract}

Case presentation: We here describe a case of epithelial-myoepithelial carcinoma (EMC) of the parotid gland, a low grade malignant tumor, with spread to an intraparotid lymph node and with $\mathrm{CT}$ and MRI findings mimicking a benign lesion.

Conclusion: All the images revealed sharply outlined profiles and a homogeneous enhancement of the nodule, suggesting a benign tumor and demonstrating that a radiological evaluation of the lesion alone may be unsatisfactory and misleading in the diagnosis of salivary gland tumours, especially in the case of low grade malignant tumors, such as EMC.

\section{Background}

Nowadays different imaging techniques offer optimal visualization of the parenchyma and of the tumors of the parotid gland. Ultrasound (US) imaging is the first-line technique in the radiological study of parotid lesions because it is an easy, quick, repeatable and non-invasive procedure. Moreover, since the parotid gland is superficial and easily accessible to the ultrasound transducer (even up to $12 \mathrm{MHz}$ [1]), US is highly sensitive. However, US can be unsatisfactory in the differential diagnosis of some tumors and inflammatory diseases and it is not adequate for all glandular areas. In fact, for tumors situated in the deep lobe, which is poorly visualized with ultrasound, as it is obscured by the mandible, it is impossible to evaluate the lesions. 
Contrast-enhanced computed tomography (CT) is the second choice radiological approach: it allows both assessment of the lesion and adequate exploration of the deeper gland parenchyma and offers highly defined spatial resolution along with a panoramic overview of the entire head-neck region.

Magnetic Resonance Imaging (MRI) is mandatory, representing a valid alternative to CT or a complementary approach to better assess the lesion. Compared to CT, MRI offers a much higher contrast resolution, but it is inadequate to evaluate the presence of calcifications.

CT and MRI can usually assume the benignancy or malignancy of a focal lesion based on simple elements of radiological findings. Benign lesions are usually small in size, well circumscribed, and have a regular morphology, as in the case of pleomorphic adenoma and Warthin's tumour. The characteristic radiological features of these lesions are represented by well defined margins, the presence of a capsule, and by bright signal intensity on T2-weighted MR images. Intralesional calcifications, easily detected by US and $\mathrm{CT}$, are another element of benignancy.

Malignant tumors are usually medium to large in size (over $3 \mathrm{~cm}$ in diameter), present undefined margins and a typical heterogeneous echo pattern because of the frequent presence of necrotic areas. MRI can show multiple round high signal intensity areas on T2WI or a large very high signal intensity area on T1WI.

Epithelial-myoepithelial carcinoma (EMC) is extremely rare compared to other carcinomas, and is considered a low malignancy neoplasm.

In the present report we describe a case of this unusual parotid gland neoplasia, radiologically simulating a benign lesion.

\section{Case presentation}

In December 2005, an 81-year-old woman came to the attention of the othorinolaryngology surgeon complaining of a painless, nodular, firm mass of the left parotid gland arisen a few months before. The patient underwent a fine needle aspiration cytology (FNAC) and 3 samples were sent to Department of Pathology. Although the CT scans suggested a benign lesion, the finding of atypical cells indicated a malignant tumor. Thus, the patient underwent a total parotidectomy with a complete excision of the lesion.

Axial contrast-enhanced CT scan (Fig. 1a) showed a welldefined, oval, smooth mass in the depth of the left parotid gland, confined to the glandular parenchyma, slight enhancing and localized in proximity to the posterior facial vein and external carotid artery, with no sign of infiltration. The parotid gland displayed a normal morfo-volumetric aspect. Coronal T2-weighted (Fig. 1b), axial T2weighted (Fig. 1c) and axial T1-weighted (Fig. 1d) images showed a well-defined nodular mass with a moderately high signal intensity in T2-weighted images (Fig. 1b-1c), and a homogeneous low signal intensity in T1-weighted images (Fig. 1d).

All the images revealed sharply outlined profiles, suggesting a benign lesion.

Grossly, the parotid gland contained a well circumscribed gray-white nodule, partially plurinodular in structure, firm on the cut surface and $2.2 \mathrm{~cm}$ in diameter.

Histologically, the tumor was characterized by a biphasic cell population represented by myoepithelial and ductal cells. The myoepithelial cells were large, polygonal, with clear-staining cytoplasm and irregularly shaped nuclei. The ductal elements were composed of cuboidal cells with eosinophilic cytoplasm and uniform, round voluminous
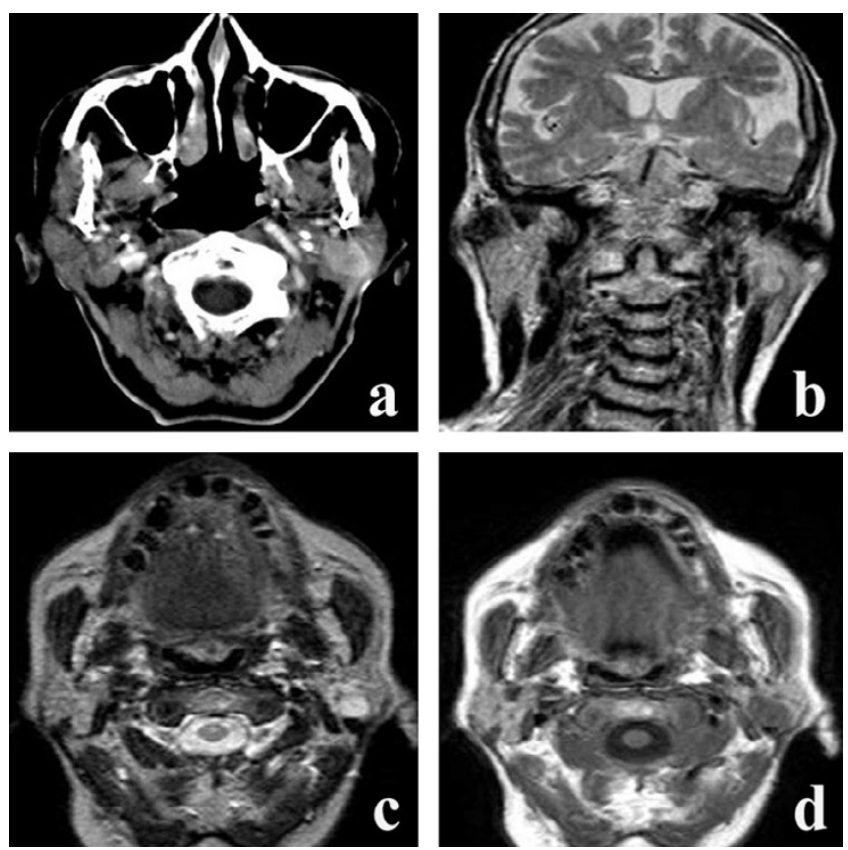

Figure I

a) Axial contrast-enhanced CT scan shows a well-defined, oval, smooth mass in the deep portion of the left parotid gland, confined in the glandular parenchyma and enhancing. The parotid gland displays a normal morfo-volumetric aspect; b) Coronal T2-weighted MR image. The mass has a homogeneous moderately high signal intensity; c) Axial T2-weighted MR image. The lesion shows well-defined nodular mass with a moderately high signal intensity; d) Axial TI-weighted image of the lesion. It shows a uniform low signal intensity. 
nuclei. The cells appeared to grow in sheets with an organoid pattern. Atypia was mild or absent. Mitotic figure count was very low. Moreover, spread to an intraparotid lymph node was observed (Fig. 2). A diagnosis of EMC was made.

US, CT and MRI are widely used in the diagnosis of parotid gland tumors. In particular CT and MRI are useful in the detection of salivary gland tumors and in assessing their extent [2]. Irregular tumor margins and infiltration into adjacent structures suggest malignancy. However, as for other human tumors, only histology can definitively establish the real nature of a lesion, given that some malignant tumors may mimic benign lesions at CT and MRI scans [3-5].

Salivary gland tumors are 12-times more frequent in the parotid gland than in the submaxillary gland, a difference that can not be explained only on the basis of gland size. Most parotid gland lesions are benign (83\%) and are largely represented by mixed-type tumors [6]. CT and MRI imaging are well characterized for the latter lesions and have also been described in the following malignant parotid tumors: carcinosarcoma [7], mucoepidermoid

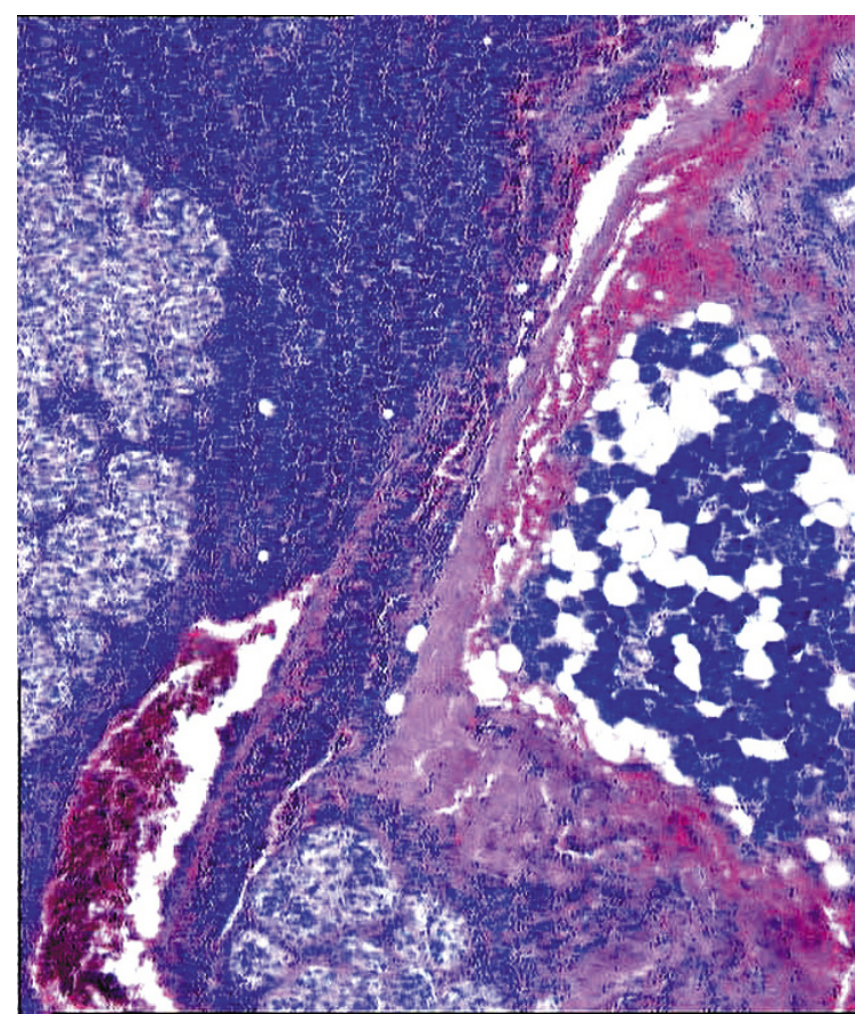

Figure 2

Parotid gland with the neoplasia and intraparotid lymph node involvement by the neoplastic proliferation (hematoxylin and eosin, 200x). carcinoma, adenoid cystic carcinoma, carcinoma ex pleomorphic adenoma, ductal carcinoma, myoepithelial carcinoma, sebaceous carcinoma and lymphoma [8-10].

Initially reported by Donath et al. [11], EMC arises predominantly in the parotid gland, more rarely in the submandibular and minor salivary glands.

To our knowledge, diagnostic imaging findings of EMC have been previously reported only few times [12-14].

In the report by Witterick et al. [12], the management of the lesion appears quite unusual. The right parotid mass was examined by US imaging in a follow-up period during which the size remained the same. Tumor resection was performed after a FNAC revealed malignant cells. Even though parotid EMC is a low grade carcinoma with a very slow growth, the absolutely imperceptible tumor enlargement described in the report seems to be contradicting with the intrinsic malignant nature of the lesion.

In the report by Silvers et al. [13], a case of EMC is radiologically described: CT scan showed a fairly well defined heterogeneous lesion with smooth margins and slight enhancement. MR images showed a lesion with intermediate T1-weighted signal intensity and a relatively high T2weighted signal intensity.

More recently, Tas et al. [14] reported a case of EMC with MRI showing an irregular and heterogeneous mass, as typically seen in other more common parotid malignant tumors.

\section{Conclusion}

In our case of parotid EMC all the images revealed sharply outlined profiles and a slight enhancement of the nodule, suggesting a benign tumor and demonstrating that a radiological evaluation of the lesion alone may be unsatisfactory and misleading in the diagnosis of salivary gland tumours, especially in the case of low grade malignant tumors, such as EMC. A FNAC of the lesion is always recommendable.

\section{Competing interests}

The author(s) declare that they have no competing interests.

\section{Authors' contributions}

$\mathrm{AF}, \mathrm{MN}, \mathrm{AC}, \mathrm{SD}$ and IP participated equally in the design of the paper and in the study of the radiological data. LM, SL and FDN participated in the study of macroscopic and microscopic features of the lesion, in the design of the study and in the drafting of the manuscript. ZCDR was involved in the drafting of the manuscript. SL revised crit- 
ically the final version of the manuscript. All authors read and approved the final manuscript.

\section{Acknowledgements}

Written consent was obtained from the patient or their relative for publication of study.

\section{References}

I. Gritzmann N, Rettenbacher T, Hollerweger A, Macheiner P, Hubner E: Sonography of the salivary glands. Eur Radiol 2003, | 3:964-975

2. Casselman JW, Mancuso AA: Major salivary gland masses: comparison of MR imaging and CT. Radiology 1987, 165:183-189.

3. Bryan RN, Miller RH, Ferreyro RI, Sessions RB: Computed tomography of the major salivary glands. $A J R A m$ J Roentgenol 1982, I 39(3):547-554.

4. Rabinov K, Kell T Jr, Gordon PH: CT of the salivary glands. Radiol Clin North Am 1984, 22:145- 159.

5. Shah GV: MR imaging of the salivary glands. Magn Reson Imaging Clin N Am 2002, 10:631-632.

6. Spero RH: Salivary neoplasms. Overview of a 35-year experience with 2807 patients. Head Neck Surg 1986, 8: 177-184.

7. King AD, Ahuja AT, To EW, Chan EC, Allen PW: Carcinosarcoma of the parotid gland: ultrasound and computed tomography findings. Australas Radiol 1999, 43:520-522.

8. Choi DS, Na DG, Byun HS, Ko YH, Kim CK, Cho JM, Lee HK: Salivary gland tumors: evaluation with two-phase helical CT. Radiology 2000, 21 4:23I-236.

9. Okahara M, Kiyosue H, Hori Y, Matsumoto A, Mori H, Yokoyama S: Parotid tumors: MR imaging with pathological correlation. Eur Radiol 2003, I3(Suppl 4):L25-L33.

10. Ikeda K, Yoshida F, Suzuki H, Oshima T, Hirano K, Takasaka T: A case report of salivary duct carcinoma. Tohoku J Exp Med I997, 183:233-238.

II. Donath K, Seifert G, Schmitz R: [Diagnosis and ultrastructure of the tubular carcinoma of salivary gland ducts. Epithelialmyoepithelial carcinoma of the intercalated ducts]. Virchows Arch A Pathol Pathol Anat 1972, 356(I):16-31. [Article in German]

12. Witterick IJ, Noyek AM, Chapnik JS, Heathcote JG, Bedard YC: Observation on the natural history of a parotid epithelialmyoepithelial carcinoma of intercalated ducts. J Otolaryngol 1993, 22:176-179.

13. Silvers AR, Som PM, Brandwein MR: Epithelial-myoepithelial carcinoma of the parotid gland. Am J Neuroradiol 1996, 17:560-562.

14. Taş A, Yağiz R, Altaner S, Koten M, Karasalihoglu AR: A case of epithelial-myoepithelial carcinoma of the parotid gland. Kulak Burun Bogaz Ihtis Derg 2003, 10:171-174.

\section{Publish with Biomed Central and every scientist can read your work free of charge}

"BioMed Central will be the most significant development for disseminating the results of biomedical research in our lifetime. "

Sir Paul Nurse, Cancer Research UK

Your research papers will be:

- available free of charge to the entire biomedical community

- peer reviewed and published immediately upon acceptance

- cited in PubMed and archived on PubMed Central

- yours - you keep the copyright

Submit your manuscript here:

http://www.biomedcentral.com/info/publishing_adv.asp
BioMedcentral 